\title{
A genome-wide association study of five meat quality traits in Yorkshire pigs
}

\author{
Qian DONG, Huiying LIU, Xinyun LI, Wei WEI, Shuhong ZHAO, Jianhua CAO (ه) \\ Key Laboratory of Agricultural Animal Genetics, Breeding and Reproduction of Ministry of Education, \\ College of Animal Science and Technology, Huazhong Agricultural University, Wuhan 430070, China
}

\begin{abstract}
Meat quality is an important trait in the pig industry. To identify genomic regions and haplotype blocks responsible for meat quality traits in pigs, a genome-wide association study was conducted for five traits including intramuscular fat content, $\mathrm{pH}$ at $45 \mathrm{~min}$ and $24 \mathrm{~h}$, drip loss within $24 \mathrm{~h}$ and water-holding capacity in 231 Yorkshire barrows using illumina porcine 60k SNP chips. The results showed that a total of 344 single nucleotide polymorphisms (SNP) were significantly associated with five meat quality traits $\left(P<1 \times 10^{-4}\right)$. Moreover, 323 SNPs were within the reported QTL regions, of which 21 were novel. Also, 158 SNPs fell into the proximal region of meat quality related genes. In addition, 25 haplotype blocks based on 116 SNPs were revealed with SNP combination patterns for five traits. Our study added new SNP information for identification of meat quality traits in pigs and will help elucidate the mechanisms of meat quality in pigs.
\end{abstract}

Keywords pig, GWAS, meat quality trait, SNP

\section{Introduction}

In the past, pig breeders have focused on increasing lean growth and decreasing backfat thickness. Unfortunately, meat qualities that influence meat flavor, tenderness and juiciness were not improved at the same time [1]. However, in modern pig breeding, improvements in these meat quality traits have been given higher priority $[2,3]$. In addition to intramuscular fat content (IMF), $\mathrm{pH}$ at $45 \mathrm{~min}$ and $24 \mathrm{~h}\left(\mathrm{pH}_{45 \mathrm{~m}}\right.$ and $\left.\mathrm{pH}_{24 \mathrm{~h}}\right)$, water-holding capacity (WHC) or drip loss within $24 \mathrm{~h}$ (DL) and color are now considered important traits for meat quality [4-6]. However, the genetic improvement of meat quality has proven to be difficult using established breeding methods

Received July 23, 2014; accepted August 8, 2014

Correspondence: jhcao@mail.hzau.edu.cn because it relies on slaughtered measurements and carcass characterizations. To identify the quantitative trait loci (QTL) affecting meat quality traits, crossed populations of pigs have been widely used [7,8]. Many candidate genes, such as PRKAG3 gene, responsible for meat qualities have been identified in different populations $[9,10]$. Genomewide association study (GWAS) is an effective strategy to identify the candidate genes or specific genome region involved in quantitative traits such as meat qualities. Taking advantage of accuracy and unbiased prediction, GWAS has become widely used in candidate gene association and marker-assisted selection (MAS). Furthermore, the application of GWAS has been extended in porcine studies based on the draft of the pig genome and high-density single nucleotide polymorphism (SNP) chips [11]. In the study reported here, 116 significant SNPs, comprising 25 haplotypes blocks related to meat qualities in a Yorkshire pig population were identified. This work will potentially benefit genome selection for meat quality and shed light on the improvement of carcass quality in pigs.

\section{Materials and methods}

\subsection{Measurement of phenotypes}

A total of 231 castrated Yorkshire pigs were fed ad libitum and slaughtered at $90 \mathrm{~kg}$ bodyweight. The longissimus dorsi muscle between the third and fourth ribs from the left carcass were excised, immediately frozen in liquid nitrogen and then stored at $-80^{\circ} \mathrm{C}$. The trait, $\mathrm{pH}_{45 \mathrm{~m}}$, was determined for one of the chops after the carcass was butchered and $\mathrm{pH}_{24 \mathrm{~h}}$ taken directly on the longissimus muscle. WHC was determined for the longissimus muscle from the second to third lumbar by the filter paper press method [12]. Two-cm-thick muscle disks were taken between the third to fourth lumbar for determination of DL. At $2 \mathrm{~h}$ postmortem, the weight (initial weight) of 
another two 2-cm-thick chops was recorded and DL determined after $24 \mathrm{~h}$. These chops were then stored in a sealed plastic bag at $4{ }^{\circ} \mathrm{C}$ for $24 \mathrm{~h}$, then blotted and reweighed (final weight). The DL at $24 \mathrm{~h}$ was calculated as follows:

$\mathrm{DL}=($ initial weight-final weight $) /$ initial weight $\times 100$,

the IMF content in thoracic-lumbar longissimus muscle was determined by the petroleum ether extraction method [13]. These phenotypic data were determined independently three times, mean and standard errors were also calculated.

\subsection{Whole genome SNP genotyping}

Genomic DNA was isolated from ear tissue using a TIANamp Genomic DNA Kit (TIANGEN, Beijing) following the manufacturer's instructions. SNP genotyping was performed using PorcineSNP60 beadchip (Illumina, USA) that contains 61177 SNP sites across the whole pig genome.

\subsection{PLINK-based GWAS}

GWAS using IMF, $\mathrm{pH}_{45 \mathrm{~m}}, \mathrm{pH}_{24 \mathrm{~h}}, \mathrm{DL}$ and WHC phenotypes was implemented by PLINK software [14] with SNP call rate $>90 \%$, minor allele frequency (MAF) $>0.03$ and $P$ value of $\chi^{2}$ test for Hardy-Weinberg Equilibrium (HWE) $>1 \times 10^{-6}$. The animals with sample call rates $<90 \%$ were excluded. The phenotypic data were subjected to logarithmic transformation for fitting normal distribution before GWAS. The PLINK-based GWAS were performed with maximum one million permutations and the threshold empirical $P$ value at $1 \times 10^{-4}$ for each phenotype.

\subsection{SNP annotation based on proximal QTLs and genes}

The significant SNPs $\left(P<1 \times 10^{-4}\right)$ were locational annotated by their proximal QTLs and genes. Previously reported QTLs for meat quality were obtained from Animal QTLdb (http://www.animalgenome.org) [15], and the SNPs that fell into the region of QTLs or genes based on linkage analysis were scanned on porcine chromosomes using the Variant Effect Predictor tool in the Ensembl website [16].

\subsection{Linkage disequilibrium analysis}

Linkage disequilibrium (LD) analysis and haplotype block detection of all significant SNPs were carried out on the chromosomal region, which contained all significant SNPs associated with each phenotype. The LD blocks were first generated within $500 \mathrm{~kb}$, then haplotype blocks were estimated by an accelerated EM algorithm [17] using Haploview software [18].

\section{Results}

\subsection{Phenotypic variation and trait correlations}

The descriptive statistics for IMF, $\mathrm{pH}_{45 \mathrm{~m}}, \mathrm{pH}_{24 \mathrm{~h}}$, DL and WHC measures of meat quality were normalized according to the corresponding sample size (Table 1 and AppendixATable S1). The range of IMF content varied from $1.18 \%$ to $3.90 \%$ across the population, and $\mathrm{pH}_{24 \mathrm{~h}}$ was significantly lower than $\mathrm{pH}_{45 \mathrm{~m}}$ as a consequence of the meat aging process. Pearson's correlation coefficients for pair-wise comparisons between the traits were calculated (Table 1). This analysis showed that $\mathrm{pH}_{24 \mathrm{~h}}$ was moderately correlated with the $\mathrm{DL}(r=0.22)$ and $\mathrm{pH}_{45 \mathrm{~m}}(r=0.24)$ parameters.

\subsection{Genome-wide association study}

The GWAS for the five traits identified 46320 SNPs over 19 porcine chromosomes (Chr.) after applying the quality control thresholds. Of these, 344 were identified as significant $\left(P<1 \times 10^{-4}\right)$ candidate SNPs associated with the different traits (Table 2 and Appendix B). Manhattan plots for five traits based on empirical $P$ values also showed that GWAS of the population had more power to detect the SNPs associated with the IMF, $\mathrm{pH}_{24 \mathrm{~h}}$ and $\mathrm{pH}_{45 \mathrm{~m}}$ than the DL and WHC traits, because more significant SNPs were identified for the first three traits. Additionally, the SNPs associated with $\mathrm{pH}_{45 \mathrm{~m}}$ and $\mathrm{pH}_{24 \mathrm{~h}}$ traits were

Table 1 The correlation matrix of five traits important for pig meat quality ${ }^{1}$

\begin{tabular}{|c|c|c|c|c|c|}
\hline Trait & $\overline{\mathrm{DL}}$ & IMF & $\overline{\mathrm{pH}_{24 \mathrm{~h}}}$ & $\mathrm{pH}_{45 \mathrm{~m}}$ & WHC \\
\hline$\overline{\mathrm{DL}^{2}}$ & 1 & 0.15 & $1.97 \times 10^{-3}$ & $1.40 \times 10^{-2}$ & $3.40 \times 10^{-4}$ \\
\hline $\mathrm{IMF}^{2}$ & 0.10 & 1 & 0.76 & 0.30 & 0.75 \\
\hline $\mathrm{pH}_{24 \mathrm{~h}}$ & 0.22 & 0.02 & 1 & $2.42 \times 10^{-4}$ & $1.51 \times 10^{-5}$ \\
\hline $\mathrm{pH}_{45 \mathrm{~m}}$ & 0.17 & -0.07 & 0.24 & 1 & 0.93 \\
\hline $\mathrm{WHC}^{2}$ & 0.26 & 0.02 & 0.29 & $6.06 \times 10^{-3}$ & 1 \\
\hline
\end{tabular}

Note: ${ }^{1}$ Five traits are intramuscular fat content (IMF), $\mathrm{pH}$ at $45 \mathrm{~min}$ and $24 \mathrm{~h}\left(\mathrm{pH}_{45 \mathrm{~m}}\right.$ and $\mathrm{pH}_{24 \mathrm{~h}}$ ), water-holding capacity (WHC) and drip loss within $24 \mathrm{~h}$ (DL). Values in the lower left cells are the Pearson coefficient of correlation and in the upper right cells the $P$ values of correlation test under null hypothesis: true correlation equal to 0 .

${ }^{2}$ The napierian based logarithm transformation for normal distribution was used for DL, IMF and WHC traits. 
Table 2 Top five significant SNPs of five traits important in pig meat quality

\begin{tabular}{|c|c|c|c|c|c|}
\hline SNP & Chr. & Position & Gene & Distance/bp & $P$-value \\
\hline \multicolumn{6}{|l|}{$\overline{\mathrm{DL}}$} \\
\hline ALGA0090332 & 16 & 38074310 & - & Intergenic & $4.89 \times 10^{-5}$ \\
\hline MARC0017494 & 16 & 39223780 & - & Intergenic & $4.89 \times 10^{-5}$ \\
\hline MARC0024258 & 16 & 39271097 & - & Intergenic & $4.89 \times 10^{-5}$ \\
\hline MARC0024258 & 16 & 39333524 & - & Intergenic & $4.89 \times 10^{-5}$ \\
\hline ASGA0073179 & 16 & 42352377 & - & Intergenic & $6.92 \times 10^{-5}$ \\
\hline \multicolumn{6}{|l|}{ IMF } \\
\hline DRGA0010405 & 10 & 30401943 & ERCC6L2 & Intron & $5.00 \times 10^{-6}$ \\
\hline ALGA0079106 & 14 & 84221823 & - & Intergenic & $5.00 \times 10^{-6}$ \\
\hline ASGA0094313 & 13 & 186196852 & - & Intergenic & $7.00 \times 10^{-6}$ \\
\hline MARC0056051 & 11 & 15872871 & ENSSSCG00000009374 & Intron & $1.10 \times 10^{-5}$ \\
\hline ALGA0076635 & 14 & 30356957 & ENSSSCG00000009761 & Intron & $1.40 \times 10^{-5}$ \\
\hline \multicolumn{6}{|l|}{$\mathrm{pH}_{24 \mathrm{~h}}$} \\
\hline H3GA0000476 & 1 & 7211765 & PARK2 & Intron & $1.00 \times 10^{-6}$ \\
\hline ALGA0005208 & 1 & 109000000 & - & Intergenic & $1.00 \times 10^{-6}$ \\
\hline MARC0056864 & 2 & 83903786 & $\mathrm{FCHO} 2$ & Intron & $1.00 \times 10^{-6}$ \\
\hline ALGA0014045 & 2 & 83953431 & FCHO2 & Intron & $1.00 \times 10^{-6}$ \\
\hline MARC0072128 & 1 & 108000000 & ENSSSCG00000004508 & 1224 & $2.00 \times 10^{-6}$ \\
\hline \multicolumn{6}{|l|}{$\mathrm{pH}_{45 \mathrm{~m}}$} \\
\hline ASGA0028877 & 6 & 86912890 & - & Intergenic & $2.00 \times 10^{-6}$ \\
\hline ASGA0103250 & 6 & 69632278 & ARHGEF19 & 1710 & $3.00 \times 10^{-6}$ \\
\hline MARC0054394 & 11 & 11385436 & - & Intergenic & $3.00 \times 10^{-6}$ \\
\hline MARC0114889 & 6 & 87000361 & - & Intergenic & $4.00 \times 10^{-6}$ \\
\hline ALGA0060823 & 11 & 11412132 & - & Intergenic & $4.00 \times 10^{-6}$ \\
\hline \multicolumn{6}{|l|}{ WHC } \\
\hline ALGA0010541 & 1 & 301699159 & ENSSSCG00000005609 & 2035 & $6.74 \times 10^{-5}$ \\
\hline ALGA0065225 & 12 & 14679312 & PECAM1 & Intron & $5.13 \times 10^{-5}$ \\
\hline ASGA0053379 & 12 & 14874907 & - & Intergenic & $7.54 \times 10^{-5}$ \\
\hline MARC0010291 & 18 & 52785500 & - & Intergenic & $1.00 \times 10^{-6}$ \\
\hline
\end{tabular}

Note: Five traits are the IMF (intramuscular fat content), $\mathrm{pH}_{45 \mathrm{~m}}\left(\mathrm{pH}\right.$ at $45 \mathrm{~min}$ ), $\mathrm{pH}_{24 \mathrm{~h}}(\mathrm{pH}$ at $24 \mathrm{~h}$ ), $\mathrm{WHC}$ (water-holding capacity) and DL (drip loss within $24 \mathrm{~h}$ ).

dispersed over the porcine genome, which indicates that the meat $\mathrm{pH}$ measures were extensively influenced by multiple gene interactions. In contrast, 12 out of 45 SNPs for IMF trait tended to be located in porcine Chr. 14 (Fig. 1).

\subsection{SNPs and functional annotation}

There were four SNPs on Chr. 16, MARC0024258, ALGA0090332, MARC0017494 and ASGA0073179, associated with the DL trait, which were located in an intergenic region. Another four SNPs on Chr. 1, 12 and 18 were associated with WHC trait and their chromosomal locations determined; ALGA0065225 in the intron of the
PECAM1 gene, ALGA0010541 in the upstream region of the ENSSSCG00000005609 gene, ASGA0053379 and MARC0010291 in the intergenic region. Forty-three SNPs associated with IMF trait included 12 intron SNPs, seven SNPs upstream from genes, four SNPs downstream from genes and 22 intergenic SNPs. The 12 intron SNPs were located in known genes $S N X 29, H S D L 1, E R C C 6 L 2$, FRMD3, APTX, TMEM132B, LOC733643 and three novel genes. Forty of the 43 SNPs involved in the QTL region were also reported in Animal QTLdb. For the $\mathrm{pH}_{24 \mathrm{~h}}$ trait, 47 of the 203 SNPs were mapped to Chr. 3, 46 to Chr. 1, 21 to $\mathrm{Chr}$. 5, $17 \mathrm{Chr} .4$ and 13 to Chr. 11, of which 73 were in gene introns, 13 in gene upstream regions and nine in gene downstream locations. Notably, the four exon SNPs 
(a)

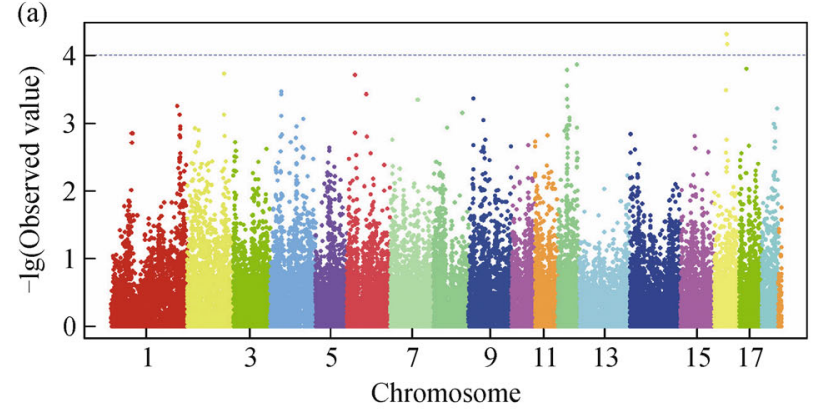

(10)

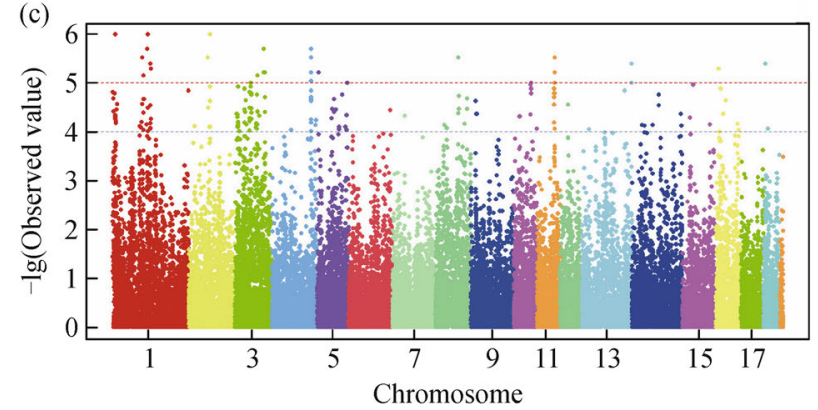

(b)

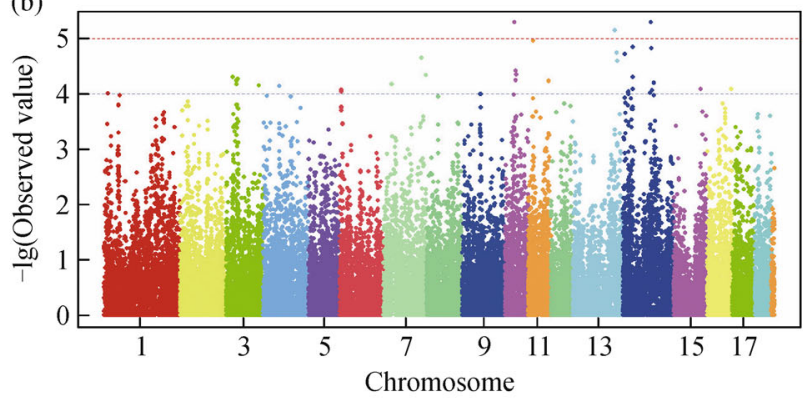

(d)

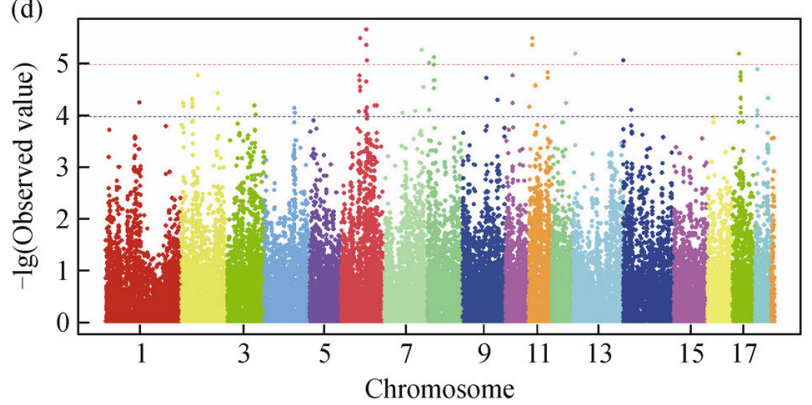

(e)

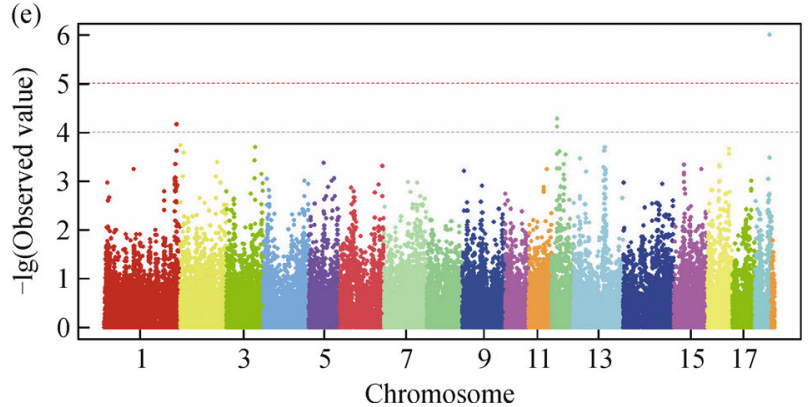

Fig. 1 Manhattan plots of GWAS results for five meat quality traits in pigs. The five traits, drip loss within 24 h (a), intramuscular fat content (b), $\mathrm{pH}$ at $24 \mathrm{~h}$ (c), $\mathrm{pH}$ at $45 \mathrm{~min}$ (d) and water-holding capacity (e), were assessed across porcine 19 chromosomes (no $\mathrm{Y}$ chromosome) based on normal distributed phenotypes. The $P$ values were calibrated as $-\lg (P)$. The horizontal lines represented the threshold $P$ value, blue for $1 \times 10^{-4}$ and yellow for $1 \times 10^{-5}$, respectively.

(H3GA0033852 in DNAJC7 gene, ALGA0087324 in EPHA4 gene, M1GA0021223 in SEMA5A gene and ALGA0103037 in ENSSSCG00000009502 gene) were synonymous variants, which did not change the amino acid but were significantly associated with meat $\mathrm{pH}$ trait. In addition, ASGA0000640 and M1GA0003969 were mapped to the $5^{\prime}$ untranslated region of ENSSSCG000 00026205 gene and 3' untranslated region of WBSCR27 gene respectively. One hundred and eighty nine SNPs were classified as meat quality related QTLs. There were 83 SNPs associated with the $\mathrm{pH}_{45 \mathrm{~m}}$ trait, of which 23 SNPs mapped on Chr. 6, 16 on Chr. 17, nine on Chr. 2, seven on Chr. 8 and six on Chr. 11 (Table 2d). The 24 intron SNPs were located in 16 genes including CRIM1, CSMD2, DENND2A, DTD1, ENOX1, FOXN3, FUT8, ITPK1, KCNN3, KIF26B, LMO2, MACROD1, POLR3F, RAB31, $S O G A 2$ and SPATA21. Four SNPs located in the upstream regions of $B A T F 2, M F A P 2, S D H B$ and $7 S K$ (BATF2) genes and three SNPs downstream of ARHGEF19,
ENSSSCG00000025105 and ENSSSCG00000003679 genes as well. Two synonymous exon SNPs, ASGA0082316 in NAT10 gene and ASGA0029060 in ENSSSCG00000003676 gene, were mapped to Chr. 2 and 6. A total 81 SNPs were classified as meat quality related QTLs.

\subsection{SNPs haplotypes}

The haplotypes composed of significant SNPs were created based on LD calculations. The SNPs with higher LD value indicated that they were genetically inherited as a group. For the $\mathrm{pH}_{24 \mathrm{~h}}$ trait, there were 11 haplotype blocks spread across Chr. 1, 3, 4 and 11, in which five blocks were in Chr. 1 and two in each of Chr. 3, 4 and 11. A total of 13 SNPs on Chr. 3 composed of two blocks, 375 and $64 \mathrm{~kb}$, with $r^{2}$ varying from 0.87 to 1.00 . One block consisted of five haplotypes, TGCTTGGT, CACCTAAC, CATCCAAC, CACCTAGC and CATCTAAC with frequencies of 0.35 , 
$0.32,0.16,0.10$ and 0.07 , respectively. The other block included three haplotypes, GAAGG, ACGAA and AAGAG, with frequencies of $0.26,0.72$ and 0.02 . The coefficient of connection between two blocks was 0.66 (Fig. 2a). In addition, five blocks on Chr. 1 were composed of 22 SNPs (Fig. 2b), two blocks on Chr. 11 composed of 13 SNPs (Fig. 2c) and two blocks on Chr. 4 composed of 11 SNPs (data not shown) were also determined by the same analysis. Moreover, two blocks, 391 and $308 \mathrm{~kb}$, on Chr. 6 contained nine SNPs associated with the $\mathrm{pH}_{45 \mathrm{~m}}$ trait. The $r^{2}$ of SNPs in the blocks ranged from 0.93 to 1.00 . There were four haplotypes in $391 \mathrm{~kb}$ haplotype, TACA, CGTC, CACA and CGTA, with frequencies of 0.50, 0.43, 0.04 and 0.03 and two haplotypes in $308 \mathrm{~kb}$ haplotype, ACCCC and GTTTA with frequencies 0.28 and 0.72 . The coefficient of connection between two blocks was 0.46 (Fig. 2d). A further five blocks composed of 23 SNPs were identified for $\mathrm{pH}_{45 \mathrm{~m}}$ trait, one block on each of Chr. 2, 8, 18 and two on Chr. 17.

\section{Discussion}

GWAS has been considered as a useful technique for candidate gene association and QTLs identification for complex traits, which are mostly focused on important production traits in domestic animals such as backfat and milk yield. In this study, a GWAS was conducted to detect potential sites responsible for the IMF, $\mathrm{pH}$, DL and WHC traits of meat in pigs. As a consequence of the close relationship between accuracy of GWAS and heritability $\left(h^{2}\right)$ of trait, many studies have reported that the heritabilities of meat quality related traits varied from 0.13 to 0.32 [19]. However, the higher $h^{2}$ of IMF trait (0.44) and $\mathrm{pH}_{24 \mathrm{~h}}$ trait $(0.32)$ found in the current work indicates that the genome-wide selection for IMF content and meat $\mathrm{pH}$ might be possible in pig population [20,21]. Based on the heritabilities and trait correlations, meat quality traits can be used in selection programs, if they are related to improved meat quality but not strongly opposed

(a)

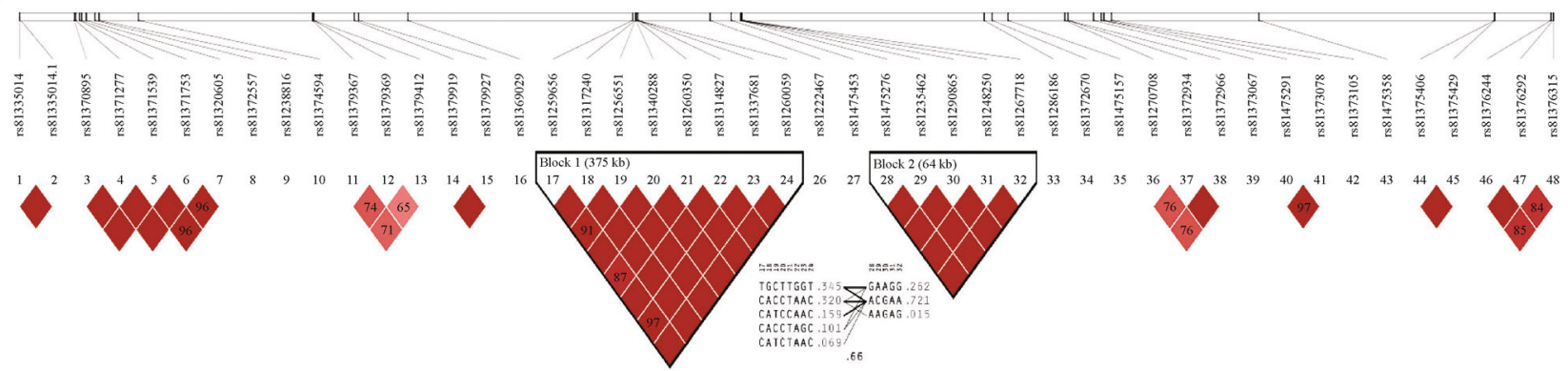

(b)

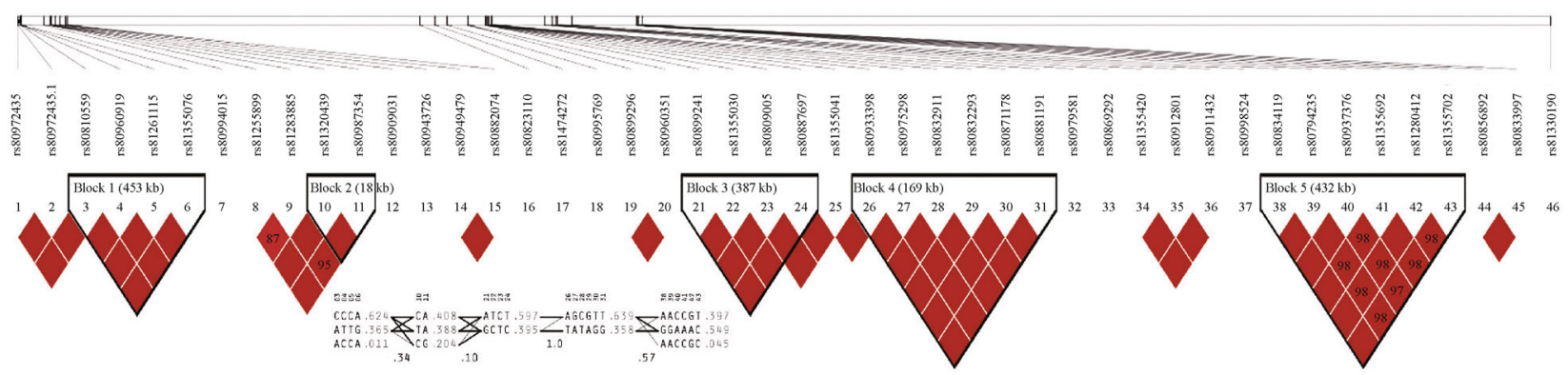

(c)

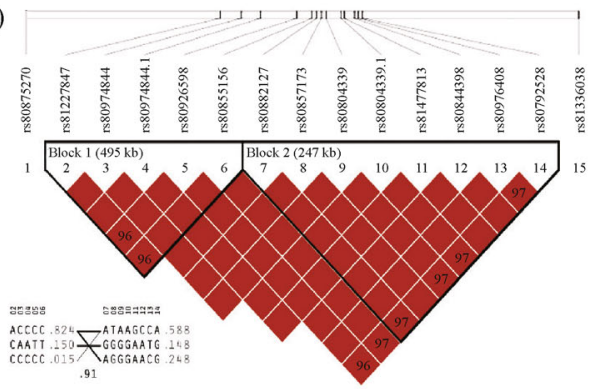

(d)

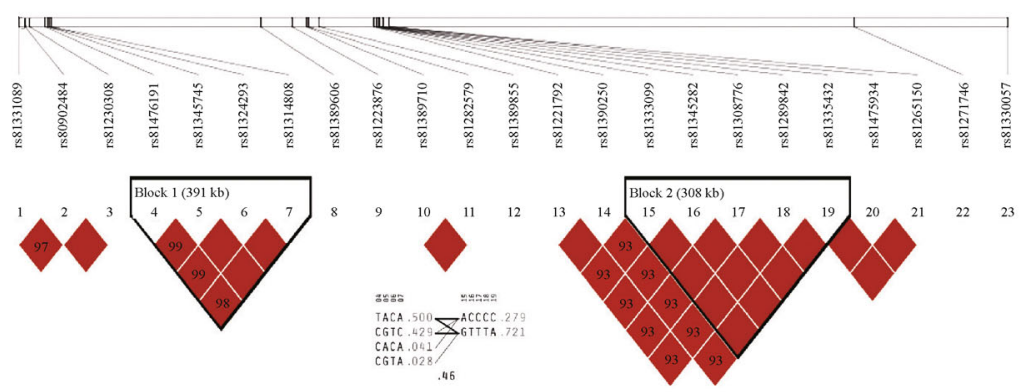

Fig. 2 Haploview plots for the pH traits in pigs based on the LD of significant SNPs. A total of 109 SNPs composed of nine haplotype blocks for $\mathrm{pH}$ at $24 \mathrm{~h}$ trait (a, b and c) and 23 SNPs forming 2 blocks for $\mathrm{pH}$ at 45 min trait (d). The coefficient of LD $\left(r^{2}\right)$ between significant SNPs was calculated within $500 \mathrm{~kb}$ chromosomal distance and the complete linkage $\left(r^{2}=1\right)$ was considered to a haplotype block represented by black diamonds. The range of blocks is shown on the top left corner in the block. The recombination rates located below the blocks represent the frequencies of haplotypes in population and the connection coefficients between the blocks are shown under the frequencies. 
to other important economic traits. Based on the comparisons of QTLs in the PigQTLdb database, a total of 358 SNPs found in the current study also validated the previous reported QTL regions related to meat qualities. ASGA0097315 on Chr.13 for $\mathrm{pH}_{24 \mathrm{~h}}$ trait falls in the intron of the FHL2 gene, which is considered as a key regulator of fatty acids metabolism and important for meat quality. In addition, this SNP and its $375 \mathrm{~kb}$ haplotype blocks were located within the reported QTL region for $\mathrm{pH}_{24 \mathrm{~h}}, \mathrm{pH}_{45 \mathrm{~m}}$ and DL traits [22,23]. MARC0110724 and MARC007 5674 related to the $\mathrm{pH}_{24 \mathrm{~h}}$ trait in the current study were also detected in another pig population [24]. These two SNP and ALGA0000021, ALGA0000046 were located in one haplotype block of $453 \mathrm{~kb}$ on $\mathrm{Chr}$. 1. Moreover, they fell into the QTLs for DL and WHC traits. In addition, MARC0110724 was mapped in the intron of the WDR27 gene that was associated with type I diabetes in previous GWAS. DNAJC3 was another candidate gene that was associated with the $\mathrm{pH}_{24 \mathrm{~h}}$ trait. The significant SNP identified in the intron of DNAJC3 was ASGA0051428. Studies have demonstrated that DNAJC3 null mice showed pancreatic-cell failure and diabetes, and the expression of $D N A J C 3$ at the protein level was increased in human T2D islets. The $\mathrm{pH}$ of pork depends mostly on the glycogen content of and glycolysis in postmortem muscle. Furthermore, this SNP was not only located within the reported QTL for DL and meat color score but also in one block of $247 \mathrm{~kb}$ on Chr. 11. ASGA0048299, as one of the significant SNPs for $\mathrm{pH}_{24 \mathrm{~h}}$, was located in the intron of $P I P 4 K 2 A$. The same locus and candidate gene for meat quality traits has been identified in the Duroc pigs. $P I P 4 K 2 B^{-/}$mice result in increasing insulin sensitivity of skeletal muscle and reducing adiposity. Insulin stimulates glucose transport into muscle and fat, where it is metabolized through glycolysis, or converted to glycogen or triglycerides, resulting in adipose tissue accumulation. Therefore, the mutation of PIP $4 K 2 B$ leads indirectly to a decrease in transport of glucose into white adipose tissues, because the increased insulin stimulates glucose transport in skeletal muscle causing a lower basal insulin-secretion requirement. Also, PIP $4 K 2 A$ might compensate for the loss of $P I P 4 K 2 B$ according to the high ratio of PIP $4 K 2 B$ expression to PIP $4 K 2 A$ expression in skeletal muscle. The H3GA0052676 SNP in the intron of the $R A B 31$ gene and a $308 \mathrm{~kb}$ haplotype block on Chr. 6 for the $\mathrm{pH}_{45 \mathrm{~m}}$ trait confirmed that the enhanced insulinstimulated Glut4 translocation and glucose uptake appeared in the knockdown of Rab31 in 3T3-L1 adipocytes. The other Chr. 6 ASGA0103250 SNP in the intron of the $A R H G E F 19$ gene for $\mathrm{pH}_{45 \mathrm{~m}}$ trait was related to adipogenesis through DNA methylation change [25]. SNP H3GA0056439 in the upstream of MFAP2 gene and a $391 \mathrm{~KB}$ haplotype block on Chr. 6 was highly related to adipocyte hypertrophy and predisposition to metabolic dysfunction, which indicated it is correlated with IMF in pigs.

\section{Conclusions}

This study of 231 Yorkshire pigs identified 344 significant SNPs $\left(P<1 \times 10^{-4}\right)$ associated with five meat quality traits, in which 323 SNPs were located in the reported QTL regions and 21 were novel. Twenty-five haplotype blocks originated from 116 SNPs provided the combination patterns of SNPs for five traits. Also, the potential genes associated with SNPs supplied candidate targets for improving meat quality in pigs. These GWAS results may provide extra landmarks to elucidate the mechanism of meat quality in pigs, as well as shedding light on the efficiency of genome wide selections.

Acknowledgements This work was supported by grants from the National Key Basic Research Program of China (2012CB124702), National Outstanding Youth Foundation of the National Natural Science Foundation of China (31025026), and the Fundamental Research Funds for the Central Universities.

Supplementary materials The online version of this article at http://dx. doi.org/10.15302/J-FASE-2014014 contains supplementary materials (Appendix A and B).

Compliance with ethics guidelines Qian Dong, Huiying Liu, Xinyun Li, Wei Wei, Shuhong Zhao and Jianhua Cao declare that they have no conflict of interest or financial conflicts to disclose.

All applicable institutional and national guidelines for the care and use of animals were followed.

\section{References}

1. Hammond K, Leitch H W, Rothschild M F, Ruvinsky A. In: Rothschild M F, and Ruvinsky A, ed. The Genetics of the Pig. 1st ed. $\mathrm{CAB}$ International, New York Genetic resources and the global programme for their management, 1998, 405-425

2. Fan B, Lkhagvadorj S, Cai W, Young J, Smith R M, Dekkers J C, Huff-Lonergan E, Lonergan S M, Rothschild M F. Identification of genetic markers associated with residual feed intake and meat quality traits in the pig. Meat Science, 2010, 84(4): 645-650

3. Franco D, Vazquez J A, Lorenzo J M. Growth performance, carcass and meat quality of the Celta pig crossbred with Duroc and Landrance genotypes. Meat Science, 2014, 96(1): 195-202

4. Srikanchai T, Murani E, Wimmers K, Ponsuksili S. Four loci differentially expressed in muscle tissue depending on waterholding capacity are associated with meat quality in commercial pig herds. Molecular Biology Reports, 2010, 37(1): 595-601

5. Fan B, Glenn K L, Geiger B, Mileham A, Rothschild M F. Investigation of QTL regions on Chromosome 17 for genes associated with meat color in the pig. Journal of Animal Breeding and Genetics, 2008, 125(4): 240-247

6. Zhang M, Wang D, Geng Z, Bian H, Liu F, Zhu Y, Xu W. The level of heat shock protein 90 in pig Longissimus dorsi muscle and its relationship with meat $\mathrm{pH}$ and quality. Food Chemistry, 2014, 165: 337-341

7. Ma J, Yang J, Zhou L, Zhang Z, Ma H, Xie X, Zhang F, Xiong X, Cui L, Yang H, Liu X, Duan Y, Xiao S, Ai H, Ren J, Huang L. 
Genome-wide association study of meat quality traits in a White Duroc $\times$ Erhualian $\mathrm{F}_{2}$ intercross and Chinese Sutai pigs. PLoS ONE, 2013, 8(5): e64047

8. Luo W, Cheng D, Chen S, Wang L, Li Y, Ma X, Song X, Liu X, Li W, Liang J, Yan H, Zhao K, Wang C, Wang L, Zhang L. Genomewide association analysis of meat quality traits in a porcine Large White $\times$ Minzhu intercross population. International Journal of Biological Sciences, 2012, 8(4): 580-595

9. Milan D, Jeon J T, Looft C, Amarger V, Robic A, Thelander M, Rogel-Gaillard C, Paul S, Iannuccelli N, Rask L, Ronne H, Lundström K, Reinsch N, Gellin J, Kalm E, Roy P L, Chardon P, Andersson L. A mutation in PRKAG3 associated with excess glycogen content in pig skeletal muscle. Science, 2000, 288(5469): 1248-1251

10. Lopez-Buesa P, Burgos C, Galve A, Varona L. Joint analysis of additive, dominant and first-order epistatic effects of four genes (IGF2, MC4R, PRKAG3 and LEPR) with known effects on fat content and fat distribution in pigs. Animal Genetics, 2014, 45(1): 133-137

11. Ramos A M, Crooijmans R P M A, Affara N A, Amaral A J, Archibald A L, Beever J E, Bendixen C, Churcher C, Clark R, Dehais P, Hansen M S, Hedegaard J, Hu Z L, Kerstens H H, Law A S, Megens H J, Milan D, Nonneman D J, Rohrer G A, Rothschild M F, Smith T P, Schnabel R D, Van Tassell C P, Taylor J F, Wiedmann R T, Schook L B, Groenen M A. Design of a high density SNP genotyping assay in the pig using SNPs identified and characterized by next generation sequencing technology. PLoS ONE, 2009, 4(8): e6524

12. Wierbicki E, Deatherage F E. Water content of meats, determination of water-holding capacity of fresh meats. Journal of Agricultural and Food Chemistry, 1958, 6(5): 387-392

13. Corrêa C C, Forato L A, Colnago L A. High-throughput nondestructive nuclear magnetic resonance method to measure intramuscular fat content in beef. Analytical and Bioanalytical Chemistry, 2009, 393(4): 1357-1360

14. Purcell S, Neale B, Todd-Brown K, Thomas L, Ferreira M A, Bender D, Maller J, Sklar P, de Bakker P I, Daly M J, Sham P C. PLINK: a tool set for whole-genome association and populationbased linkage analyses. American Journal of Human Genetics, 2007, 81(3): 559-575

15. Hu Z L, Park C A, Wu X L, Reecy J M. Animal QTLdb: an improved database tool for livestock animal QTL/association data dissemination in the post-genome era. Nucleic Acids Research, 2013, 41(D1): D871-D879
16. McLaren W, Pritchard B, Rios D, Chen Y, Flicek P, Cunningham F. Deriving the consequences of genomic variants with the Ensembl API and SNP Effect Predictor. Bioinformatics, 2010, 26(16): 20692070

17. Qin Z S, Niu T, Liu J S. Partition-ligation-expectation-maximization algorithm for haplotype inference with single-nucleotide polymorphisms. American Journal of Human Genetics, 2002, 71(5): $1242-1247$

18. Barrett J C, Fry B, Maller J, Daly M J. Haploview: analysis and visualization of LD and haplotype maps. Bioinformatics, 2005, 21 (2): 263-265

19. Larzul C, Lefaucheur L, Ecolan P, Gogué J, Talmant A, Sellier P, Le Roy P, Monin G. Phenotypic and genetic parameters for longissimus muscle fiber characteristics in relation to growth, carcass, and meat quality traits in large white pigs. Journal of Animal Science, 1997, 75(12): 3126-3137

20. Horák P, Stratil A, Svatonová M, Mastalková L, Patáková J, Van Poucke M, Bartenschlager H, Peelman L J, Geldermann H. Polymorphism screening and mapping of nine meat performancerelated genes in the pig. Animal Genetics, 2010, 41(3): 334-335

21. Lee K T, Byun M J, Kang K S, Hwang H, Park E W, Kim J M, Kim T H, Lee S H. Single nucleotide polymorphism association study for backfat and intramuscular fat content in the region between SW2098 and SW1881 on pig chromosome 6. Journal of Animal Science, 2012, 90(4): 1081-1087

22. Duan Y Y, Ma J W, Yuan F, Huang L B, Yang K X, Xie J P, Wu G $Z$, Huang L S. Genome-wide identification of quantitative trait loci for pork temperature, $\mathrm{pH}$ decline, and glycolytic potential in a largescale White Duroc $\times$ Chinese Erhualian resource population. Journal of Animal Science, 2009, 87(1): 9-16

23. Liu G, Jennen D G, Tholen E, Juengst H, Kleinwächter T, Hölker M, Tesfaye D, Un G, Schreinemachers H J, Murani E, Ponsuksili S, Kim J J, Schellander K, Wimmers K. A genome scan reveals QTL for growth, fatness, leanness and meat quality in a Duroc-Pietrain resource population. Animal Genetics, 2007, 38(3): 241-252

24. Sanchez M P, Tribout T, Iannuccelli N, Bouffaud M, Servin B, Tenghe A, Dehais P, Muller N, Del Schneider M P, Mercat M J, Rogel-Gaillard C, Milan D, Bidanel J P, Gilbert H. A genome-wide association study of production traits in a commercial population of Large White pigs: evidence of haplotypes affecting meat quality. Genetics Selection Evolution, 2014, 46(1): 12

25. Horii T, Morita S, Kimura M, Hatada I. Epigenetic regulation of adipocyte differentiation by a Rho guanine nucleotide exchange factor, WGEF. PLoS ONE, 2009, 4(6): e5809 